\title{
Discurso del Dr. Juan Manuel Sotelo, representante de OPS/OMS en Chile
}

Es muy grato estar participando de esta ceremonia de apertura y ser co-organizador de este primer congreso, que hoy se realiza y que posibilita que las mejores cabezas que están en el tema, hagan un balance de donde estamos y contribuyan con sus trabajos y reflexiones a construir una mejor salud para todos los chilenos.

Permítanme referirme a tres asuntos de particular relevancia como son los principios, los ámbitos y las oportunidades para avanzar en salud.

En primer lugar, los principios que deben estar insoslayablemente presentes son:

- La equidad y su búsqueda, para superar las diferencias injustas entre grupos y subgrupos de la población. La persistencia de la exclusión social y de la inequidad en la distribución de los beneficios del desarrollo, continúan siendo obstáculos para un desarrollo humano incluyente y para mejorar las condiciones de salud.

- La ética como responsabilidad, especialmente cuando la salud mueve 1.8 billones de dólares por día en el mundo según información económica de las naciones unidas y donde los intereses de las partes involucradas pudieran alejarse de la búsqueda de la salud para todos.

- La salud es un derecho humano fundamental y aquí me gustaría destacar que los sistemas de protección social en salud constituyen el instrumento estelar para el logro de salud como derecho y la inclusión social. Para esto, la protección social en salud debe ser diseñada como una política pública de alto nivel que elimine o disminuya la exclusión social en salud.
En segundo lugar, los ámbitos privilegiados para poder actuar con mejores resultados, son aquellos propios de la construcción de políticas públicas. Hay países en las Américas que han logrado construir buenas políticas que impactan favorablemente a la salud, que van desde la protección social, con acceso universal y equitativo, hasta el abordaje de los determinantes sociales de la salud, enfoque donde chile está participando pioneramente en el mundo al tomar con seriedad el nuevo marco de intersectorialidad que representa este camino así como las varias conexiones sociales de la salud. "Chile crece contigo" es un muy buen ejemplo.

Otro ámbito privilegiado es el de los sistemas de salud basados en la atención primaria que garantizan de manera efectiva el acceso universal y equitativo, a una atención con servicios de salud solidarios y participativos, al tiempo que aseguran eficiencia, eficacia y calidad.

La formación de los recursos humanos, la fuerza laboral en salud, constituye otro ámbito excepcionalmente fértil para avanzar en salud.

Les recuerdo que la organización mundial de la salud ha decidido que ésta es la década de los recursos humanos en salud, que nuestros planes contribuyan pues a articular a las personas que trabajan en salud, a las políticas, programas y desempeño que se requiera.

Finalmente, quiero referirme a las oportunidades. Se acaba de aprobar en la última asamblea de la OEA en Panamá, la agenda de salud para las Américas, instrumento de los estados miembros de la Organización Panamericana de la Salud, que delimita el escenario de acción en ocho áreas y permítanme mencionarlas: 
- Fortalecer la autoridad sanitaria nacional

- Abordar los determinantes de la salud

- Aumentar la protección social y el acceso a servicios de salud de calidad;

- Disminuir las desigualdades en salud entre los países y las inequidades al interior de los mismos

- Reducir los riesgos y la carga de enfermedad

- Fortalecer la gestión y desarrollo de los trabajadores de la salud

- Aprovechar los conocimientos, la ciencia y la tecnología

- Fortalecer la seguridad sanitaria

Esta agenda nos marca el camino para cerrar la brecha ética y social del trabajo que falta por hacer en salud y el cumplimiento de las metas del milenio.

Otra oportunidad es la celebración de los 30 años de alma ata y la renovación de la atención primaria de la salud. Los países se encuentran preparando estudios y evaluaciones. Sé de por lo menos de dos desarrollos significativos que están en preparación en chile.
El próximo año en mayo de 2008, tendremos el informe de la comisión de determinantes sociales de la salud que promete darnos muchas luces producto de un trabajo sin precedentes de nueve redes de conocimiento.

La puesta en marcha del nuevo reglamento sanitario internacional es otra oportunidad y donde chile contribuye con su experiencia muy activamente.

La participación del país en las actividades de salud en la comunidad andina de naciones y en el Mercosur está representando una acción entre países que es muy beneficiosa.

Pero tal vez la oportunidad más cercana para avanzar sea la propia reforma de la salud chilena, camino a enriquecerse con los planes de salud pública y una mayor cobertura de problemas de salud con garantías explícitas.

A nombre de la Organización Panamericana de la Salud y de la Organización Mundial de la Salud, deseo que este Primer Congreso de Salud Pública sea un éxito y que aporte con ideas, trabajo serio y compromiso a una ciudadanía plena y saludable. 